\title{
Temporal changes in diastolic function measured by volumetric CMR after ST Elevation Myocardial infarction
}

\author{
Gopal Ghimire*, Jyotshana Shrestha, Manuel A Gonzalez, Ana Barac, Rebecca Torguson, William O Suddath, \\ Lowell F Satler, Augusto D Pichard, Ron Waksman, Anthon R Fuisz, Gaby Weissman
}

From 2011 SCMR/Euro CMR Joint Scientific Sessions

Nice, France. 3-6 February 2011

\section{Objective}

We aim to evaluate changes in diastolic function after ST elevation myocardial infarction (STEMI) using volumetric cardiac magnetic resonance imaging (CMR), as well as the relation of diastolic parameters to baseline variables including peak troponin-I and baseline left ventricular ejection fraction (LVEF).

\section{Background}

Diastolic dysfunction is one of the earliest manifestations of cardiac ischemia. However, the response to reperfusion of diastolic filling parameters in patients with STEMI undergoing primary percutaneous coronary intervention (PCI) is not well elucidated. Using volumetric analysis we aimed to define the temporal change in diastolic function after primary PCI.

\section{Method}

23 patients with STEMI undergoing primary PCI were prospectively enrolled and sequential CMR imaging was performed within 96 hours of admission and at 1 month follow up. LV volumetric quantification was performed (QMass MR, Medis, Leiden, The Netherlands) with manual planimetry of the endocardial contours in all temporal phases of the contiguous short-axis slices. Systolic parameters were obtained. Diastolic CMR parameters were derived including peak filling rate (PFR) and its index normalized to end diastolic volume (NPFR), time to peak filling rate (TPFR), diastolic volume recovery $\left(D V R_{80}\right)$ : proportion of diastole required for recovery of 80 percentage of stroke volume as well as the ratio of the biphasic early (E) and late (A) filling profiles (E/A ratio).

Washington Hospital Center, Washington, DC, USA
The change in those parameters was then correlated to peak troponin-I and baseline LVEF.

\section{Results}

At one month follow-up LVEF improved from $49 \%$ (interquartile range (38-61) at baseline to 57\% (49-62), $\mathrm{p}=0.04$. There were no significant changes in LV volumes; LV end diastolic volume changed from $194.5 \mathrm{ml}$ ( $152.9-237.0)$ to $192 \mathrm{ml}(152.5-221.7), \mathrm{p}=0.14)$ and LV end systolic volume from $100 \mathrm{ml}(65.0-125.8)$ to $87.71 \mathrm{ml}(52.8-96.0), \mathrm{p}=0.08$. The changes in the diastolic parameters are depicted in table 1 . PFR, TPFR and NPFR did not change significantly however E/A increased from 1.06 to 1.63 while $\mathrm{DVR}_{80}$ decreased from $86.1 \%$ to $83.2 \%$. Figure 1 .

The change in $\mathrm{DVR}_{80}$ and E/A ratio was not correlated with peak troponin, baseline LVEF, or baseline LV volumes.

\section{Conclusion}

Improvement in LVEF with reperfusion did not translate to improvement in PFR, NPFR and TPFR which have been traditionally used as indices of diastolic function.

\section{Table 1}

\begin{tabular}{llll}
\hline $\begin{array}{l}\text { Diastolic } \\
\text { parameters }\end{array}$ & Index MRI & Follow up MRI & \\
\hline DVR $_{8} 0$ & $86.1(91.53-90.12)$ & $83.2(75.15-84.94)$ & $P=0.02$ \\
E/A ratio & $1.06(0.85-1.7)$ & $1.63(0.9-2.1)$ & $\mathrm{P}=0.03$ \\
PFR (ml/sec) & 519.75 & $530(469.6-$ & $\mathrm{P}=\mathrm{ns}$ \\
& $(409.17-603.2)$ & $661.25)$ & \\
TPFR (m sec) & $131.47(104.58-$ & 134.19 & $\mathrm{P}=\mathrm{ns}$ \\
& $156.96)$ & $(116.21-164.31)$ & \\
NPFR & $2.72(2.31-3.34)$ & $2.8(2.29-3.54)$ & $\mathrm{P}=\mathrm{ns}$ \\
\hline
\end{tabular}




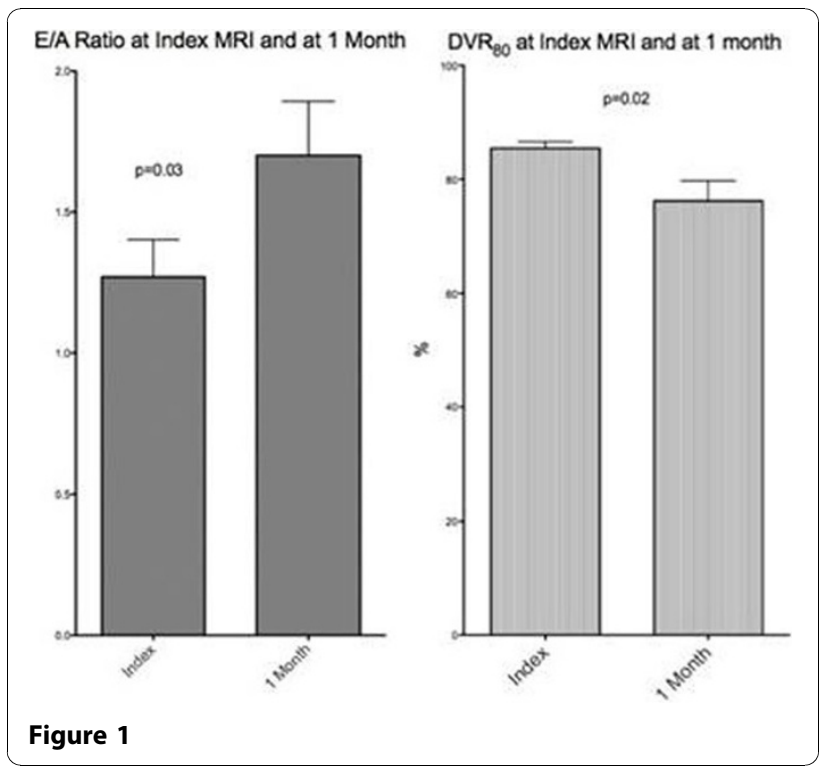

On the other hand, significant changes were seen in $\mathrm{DVR}_{80}$ and E/A ratio. These parameters may serve as targets from future investigation in the effect of revascularization on myocardial function.

Published: 2 February 2011

doi:10.1186/1532-429X-13-S1-P138

Cite this article as: Ghimire et al:: Temporal changes in diastolic

function measured by volumetric CMR after ST Elevation Myocardial

infarction. Journal of Cardiovascular Magnetic Resonance 2011 13(Suppl 1):

P138.
Submit your next manuscript to BioMed Central and take full advantage of:

- Convenient online submission

- Thorough peer review

- No space constraints or color figure charges

- Immediate publication on acceptance

- Inclusion in PubMed, CAS, Scopus and Google Scholar

- Research which is freely available for redistribution

Submit your manuscript at www.biomedcentral.com/submit
C Biomed Central 